\title{
Fuzzy mamdani logic inference model in the loading of distribution substation transformer SCADA system
}

\author{
Rahma Farah Ningrum, Riki Ruli A. Siregar, Darma Rusjdi \\ Faculty of Telematics for Energy, Informatics Program, Institut Teknologi PLN, Jakarta, Indonesia
}

\begin{tabular}{l} 
Article Info \\
\hline Article history: \\
Received Feb 20, 2020 \\
Revised Dec 7, 2020 \\
Accepted Mar 26, 2021 \\
\hline
\end{tabular}

\section{Keywords:}

Fuzzy mamdani

IoT

SAIFI SAIDI

SCADA

Telemetry

\begin{abstract}
The research objective of supervisory control and data acquisition (SCADA), with fuzzy Mamdani logic simulation on the loading section of distribution transformer substations. Data acquisition is available when saving SAIFI SAIDI data and storing the results of monitoring equipment. The method used is Mamdani fuzzy logic, there are two input variables, namely current and voltage devices. The membership function in Mamdani fuzzy logic has been created based on the input current and voltage variables. Currently: parameter $\{0,600\}$ low is created $\{0,350,450,600\}$, normal $\{400-650\}$ parameter is created $\{400,500,550,650\}$, parameter high $\{\geq 600\}$ is created $\{600,650,750,1000\}$, when determining the voltage: low $\{\leq 10.5\}$ parameters $\{04710.5\}$, normal $\{9-14\}$ parameters $\{9,10,13,14\}$ and high $\{\geq 13\}$ - parameters $\{13,14,15,16\}$. Based on the results of the Mamdani logic rule test on the output current containing a transformer and a voltage sensor, the results obtained are IF (normal current; (630) AND voltage (high); (13.2) (high load transformer). The components in the simulation tool include miniature substations made with the $1 \mathrm{~A}$ travel substation model, $3 \mathrm{~A}$ substation as the main substation, the relay as distribution substation as the monitoring application. Telestatus and Telecontrol use a microcontroller. Initial scenario. After substation is resumed, data is stored after downtime, service life, duration, and data period. Initial scenario After substation is resumed, data is stored after downtime, service life, duration, and data period.
\end{abstract}

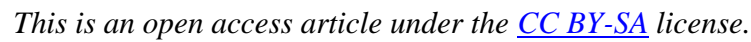

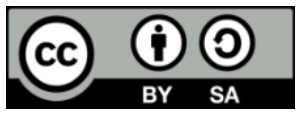

\section{Corresponding Author:}

Riki Ruli A. Siregar

Faculty of Telematics for Energy, Informatics Program

Institut Teknologi PLN, Jakarta, Indonesia

Email: riki.ruli@itpln.ac.id

\section{INTRODUCTION}

SCADA is a system that can carry out the process of data acquisition, control, and monitoring of industrial control systems [1] . The SCADA element consists of three parts, namely the field device, remote terminal unit (RTU), master terminal unit (MTU) [2], [3]. Data from the field device is sent to the RTU (PLC), then sent to the MTU. Data communication between PLC and MTU uses RS232C serial communication. Data from MTU will be sent to the server [4]-[6]. The reliability of the SCADA system affects the operation of the micro-network [7]. The effective design of the supervision and data acquisition control system (SCADA) system for micro networks including front-end processing modules, communication gateway modules, and surveillance control modules is presented in this study and then the SCADA micro-network system is built [3], [8]. The actual micro-network operation test is done using the SCADA system. The experimental results show that the design and method of implementing a microSCADA system is practical and feasible [4], [9], [10]. Research studies with remote electricity monitoring 
and control using a web browser using TCP/IP protocols that support cellular systems [11]. It contains basic analog input/output and basic digital input/output which can be applied to motor drivers and inverters for integration with remote SCADA systems based on IoT, and thus achieve efficient power management [12][14]. The study was conducted using a model based on the fuzzy inference system (FIS) to evaluate the performance of the block cipher algorithm based on three current metrics [15]-[17]. Two types of FIS models, the Mamdani FIS model, and the Sugeno FIS model were used for this evaluation. The fuzzy inference system was developed for the block cipher algorithm using two types of fuzzy models [18-20]. The arena of the importance of performance in our online system compares the Mamdani model, which was used before, with the Sugeno formulation using four types of membership function methods (MF) [21]. The first method of the triangular membership function uses the average, minimum and maximum values of the histogram attribute. The second approach produces a triangular membership function using a peak and standard deviation of attribute values. The third procedure produces a gaussian membership function using the mean and standard deviation the histogram attribute values. The fourth approach produces a gaussian membership function using the peak and standard deviations of the histogram attribute values [22], [23].

\section{RESEARCH METHOD}

Comparison with other studies is the SCADA model with fuzzy Mamdani logic. Fuzzy logic method is a method that can be applied to data input in the form of linguistic variables, namely variables that are natural or obtained from humans. Output obtained by the method of fuzzy set [24]-[26]. The system design that will be made has several steps in its completion. The design that is designed is necessary so that the system to be implemented does not go out of its original destination [27], [28]. There are 3 transformers where each transformer has a current sensor and a voltage sensor. The transformer consists of a current sensor and a voltage sensor (current and voltage value detector), a DC Step Up to add voltage, an LsED indicator for each substation, a buzzer as an alarm, an LCD and a power supply. Whereas for human machine interface (HMI) there is an interface on the PC with the vb.net application which will monitor the SCADA system on the transformer or substation, this interface uses communication connected to a serial USB where to connect between the microcontroller and the PC [4]. The system will be displayed in the form of monitoring devices in real-time in terms of telemetering functions measuring current, voltage, and power regulation while functions in telecontrolling and telesignalling in turning off and turning on substations or performing substation recovery systems with notification at the time of travel, while for data acquisition located monitoring history and SAIFI SAIDI reports on substation trips.

In the system in Figure 1, system input consists of:

1. The transformer measurement input data is detected on the current and voltage sensors.

2. DC step up CN6009 is used to raise the voltage to a voltage higher than the DC load input source

3. Monitoring button device to start the monitoring tool process entering current and voltage measurements in real-time and to reset the monitoring process, the Reset button is used.

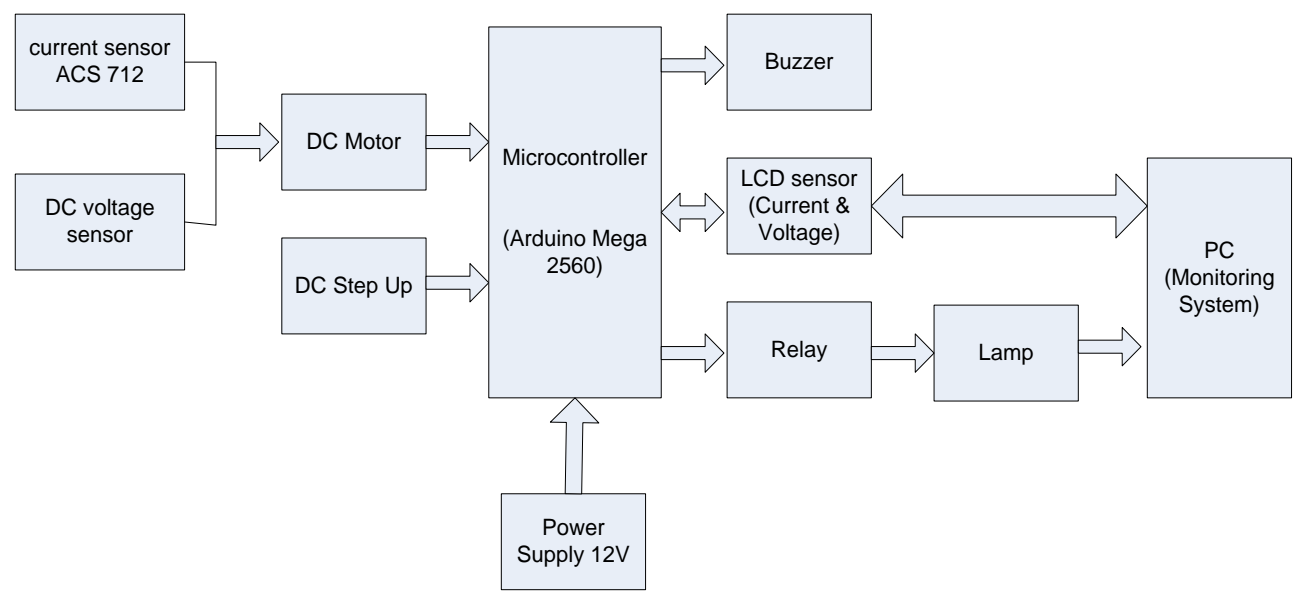

Figure 1. Tool block 1 transformer diagram

Figure 2, in the process simulation scheme, the device circuit scheme is only a microcontroller that will control the entire process in this monitoring system. Where the sensor will work if there is a moving DC

Fuzzy mamdani logic inference model in the loading of distribution substation... (Rahma Farah Ningrum) 
load, from a power supply source, the next process is to monitor the devices that are on the application interface that has been designed [29]. In the output part of this system consists of:

1. In a substation and transformer monitoring application system that displays current and voltage measurements in real-time.

2. Light emitting diode (LED) indicator

3. Green indicator LED functions as a live substation indicator

4. The red LED indicator functions as a dead switch.

5. The entire substation travel process will be automatically saved to SAIDI/SAIFI.

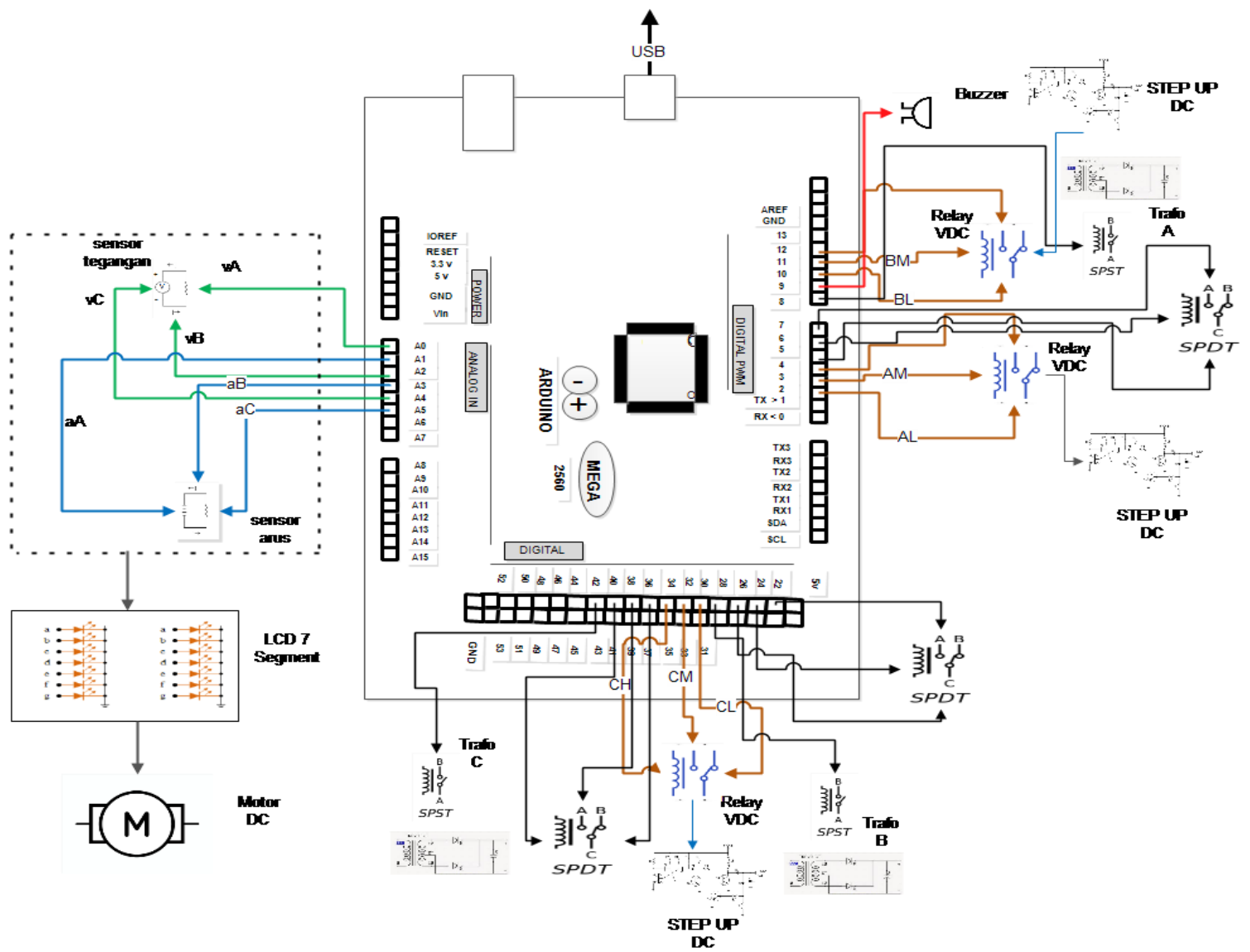

Figure 2. Schematic of a device circuit

The design of the monitoring application uses fuzzy logic inference techniques with the Mamdani fuzzy method based on the following steps [28]:

1. Enter variables in the form of current and voltage

2. Output variables in the form of loading transformers

3. Fuzzy Mamdani Inference is generated from entering variables, output variables, and knowledge base.

4. Knowledge Base based on 9 Rules namely:

a. [R1] If the Current is Low and the Voltage is Low then the Load of sTransformer is Low.

b. [R2] If the Current is Normal and the Voltage is Low then the Load of the Transformer is Low.

c. [R3] If the Current is High and the Voltage is Low, the Load Transformer is Low.

d. [R4] If the Current is Low and the Voltage is Normal, then the Transformer Loading is Normal.

e. [R5] If the Current is Normal and Normal Voltage, then Normal Transformer Loading.

f. [R6] If the High Current and Voltage are Normal, the Transformer Loading is Normal.

g. [R7] If the Current is Low and the Voltage is High then the Load Transformer is High.

h. [R8] If the Current is Normal and the Voltage is High, the Load Transformer is High

i. [R9] If the High Current and High Voltage the Load Transformer is High. 


\section{RESULTS AND ANALYSIS}

After performing an experiment or operation, the data is collected in a database. The data processing collected will be displayed in this form as shown in Figure 3. The results of the data processing are called SAIDI and SAIFI. SAIDI is the result of a long blackout in a second, while SAIFI is how many feeders experience problems in a day. Limits for SAIDI and SAIFI are per second and per day. This is taken because it follows the simulation that will be carried out in real-time.

In this sensor system, as shown in Figure 4 and Figure 5, the method used is fuzzy mamdani logic, there are two input variables, namely current and voltage. Here are the classifications:

- Current: $\{$ Low, Normal, High $\}$

- Voltage: $\{$ Low, Normal, High $\}$

Output:

- $\quad$ Transformer Load: \{Low, Normal, High\}

$[x]\left\{\begin{array}{cc}0 ; & x \leq \text { a or } x \geq d \\ (x-a) /(b-a) & a<x \leq b \\ 1 ; & b<x \leq c \\ (d-x) /(d-c) & c<x \leq d\end{array}\right.$

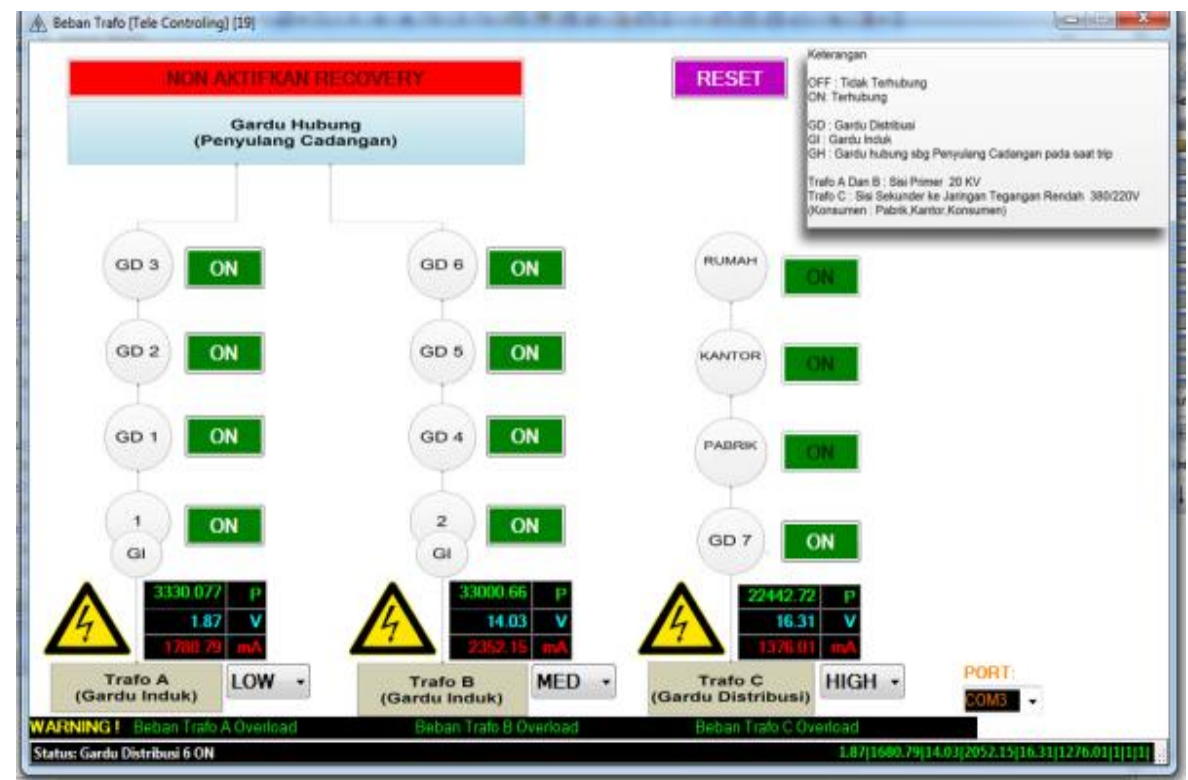

Figure 3. Interface monitoring scada software

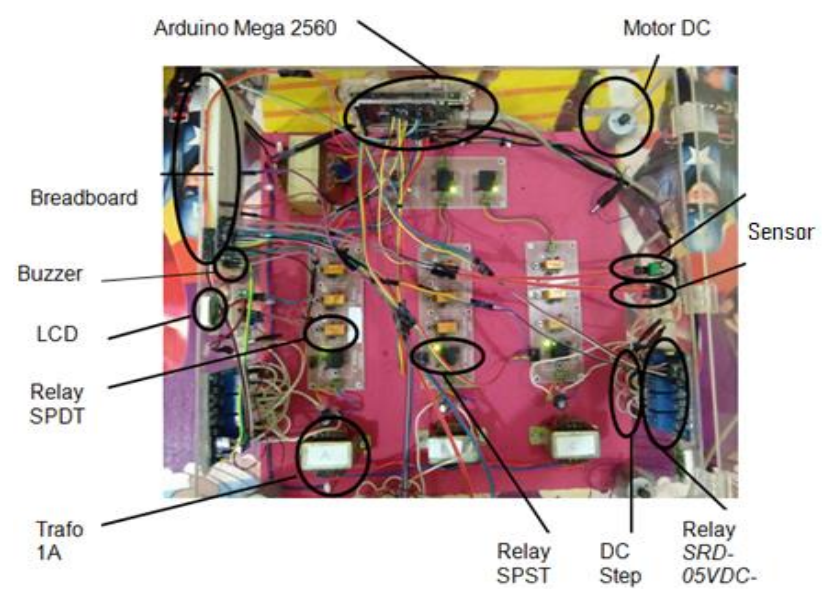

Figure 4. SCADA simulation tool scheme 


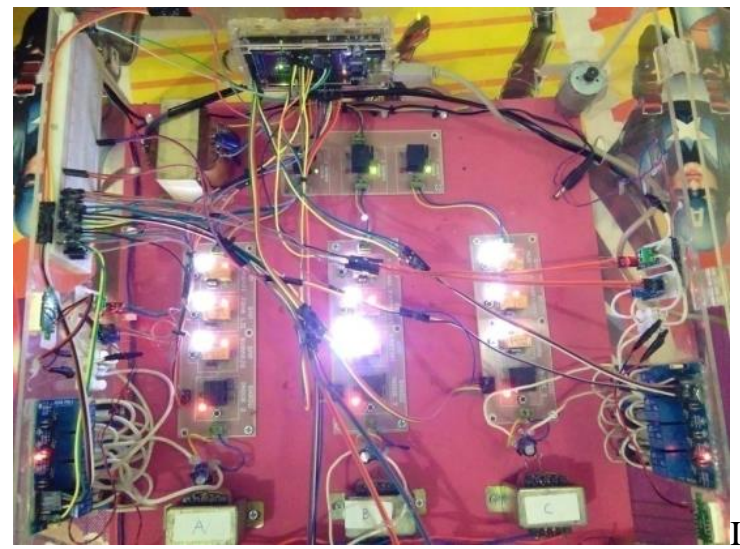

Figure 5. SCADA running simulation

The membership function in Mamdani fuzzy logic has been created based on input current and voltage variables. Currently: Low $\{0,600\}$ parameters created $\{0,350,450,600\}$, Normal $\{400-650\}$ parameters created $\{400,500,550,650\}$, parameters High $\{\geq 600\}$ created $\{600,650,750,1000\}$, when determining voltage: low $\{\leq 10.5\}$ from Parameter $\{04710.5\}$, Normal $\{9-14\}$ Parameters $\{9,10,13,14\}$ and high $\{\geq 13\}$ - Parameters $\{13,14,15,16\}$. The following rules are obtained:

[R1] IF (Low Current) AND (Low Voltage) THEN (Low Transformer Load)

[R2] IF ([Normal Current) AND (Low Voltage) THEN (Low Transformer Load)

[R3] IF (High Current) AND (Low Voltage) THEN (Low Transformer Load)

[R4] IF (Low Current) AND (Normal Voltage) THEN (Normal Transformer Load)

[R5] IF (Normal Current) AND (Normal Voltage) THEN (Normal Transformer Load)

[R6] IF (High Current) AND (Normal Voltage) THEN (Normal Transformer Load)

[R7] IF (Low Current) AND (High Voltage) THEN (High Transformer Load)

[R8] IF (Normal Current) AND (High Voltage) THEN (High Transformer Load)

[R9] IF (High Current) AND (High Voltage) THEN (High Transformer Load)

The rules on the fuzzy mamdani logic used are the MIN Method.

[R5] IF (Normal Current) AND (Normal Voltage) THEN (Normal Transformer Load) [R6] IF (High Current) AND (Normal Voltage) THEN (Normal Transformer Load) [R8] IF (Normal Current) AND (High Voltage) THEN (High Transformer Load) [R9] IF (High Current) AND (High Voltage) THEN (High Transformer Load)

$$
\begin{aligned}
& \mu \text { Normal Current }[630] \\
& =(20)(100)=0.2 \\
& \mu \text { High Current }[630] \\
& =(30)(50)=0.6 \\
& \mu \text { Normal Voltage }[13.23] \\
& =(0.77)(1)=1 \\
& \mu H i g h \text { Voltage }[13.23] \\
& =(0.23)(1)=1
\end{aligned}
$$

$\alpha$-predicate (fire strength) for each rule is:

[R5] IF (Normal Current) AND (Normal Voltage) THEN (Normal Transformer Load) $\alpha$ - $^{\text {predicate }_{5}} \quad=$ Current Current Normal $\cap$ Normal Voltage

$=\min (\mu$ ArusNormal $(630), \mu(\mu$ Normal Voltage $(13.23))$

$=\min (0.2 ; 0.77)$

$=0.2$

[R6] IF (High Current) AND (Normal Voltage) THEN (Normal Transformer Load)

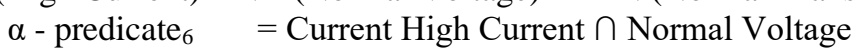




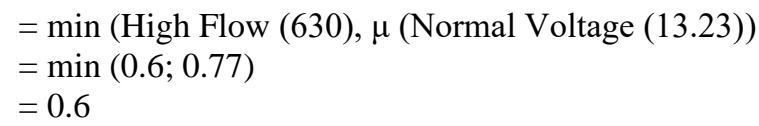

[R8] IF (Normal Current) AND (High Voltage) THEN (High Transformer Load)

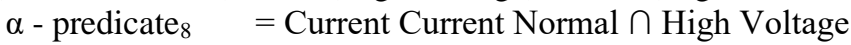

$=\min (\mu$ Normal Normal (630), $\mu$ (High Voltage (13.23))

$=\min (0.2 ; 0.23)$

$=0.2$

[R9] IF (High Current) AND (High Voltage) THEN (High Transformer Load)

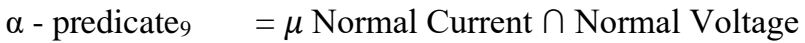

$=\min$ (normal current (630), $\mu$ (normal voltage (13.23))

$=\min (0.6 ; 0.23)$

$=0.23$

The next process is the result of the functional implications of each rule, the MAX method is used to compose all rules. The result is as shown in Figure 6.

The test results are shown in Figure 7, of the 9 Rules for testing the output of input currents containing transformers and voltage sensors, the results obtained in rule [8] with IF inference (Normal Current; (630) AND (High) Voltage; (13.2) TRAFFIC) (High Transformer Load).

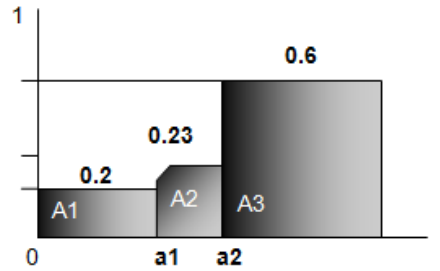

Figure 6. Composition between rules

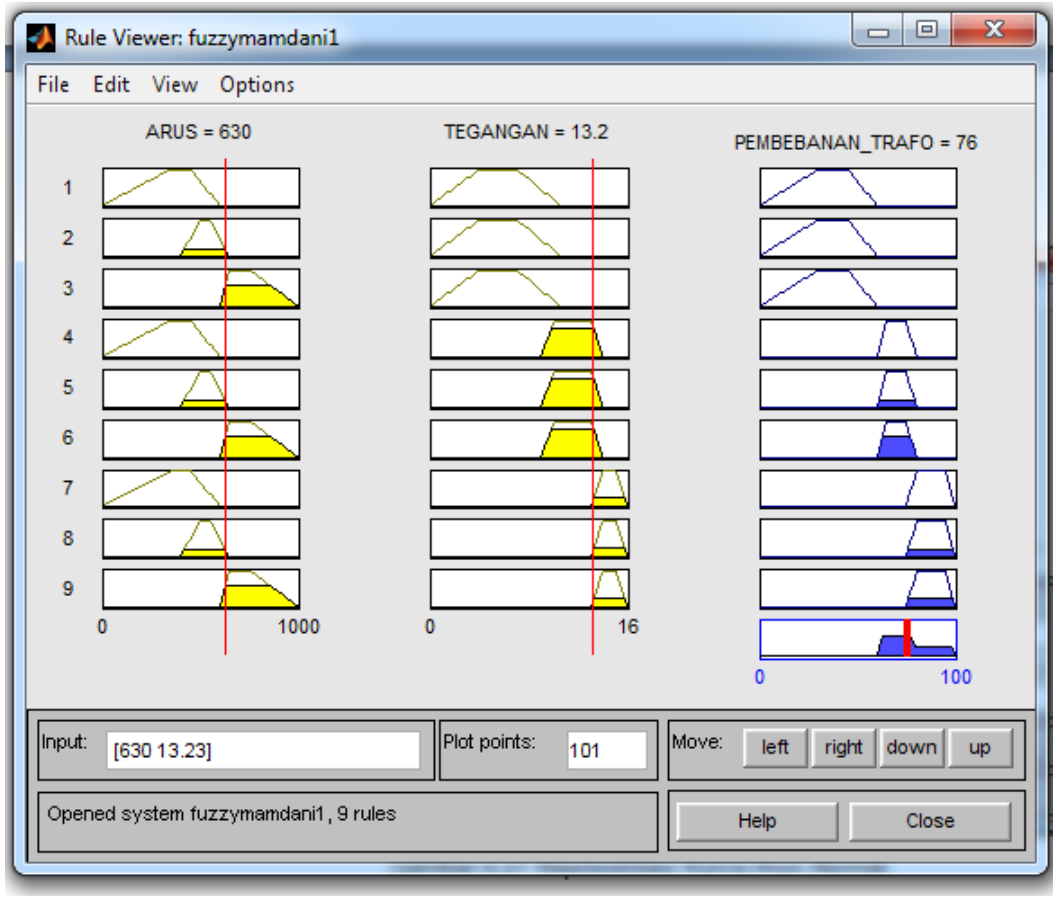

Figure 7. Display of results R [8] in Matlab

\section{CONCLUSION}

The application of Mamdani fuzzy logic to learning media Introduction to SCADA technology is a telemetry aspect. The completion of Mamdani fuzzy logic is made in 3 stages, namely the formation of Mamdani fuzzy logic, the application of the implication function, and the max method. The transformer load condition monitoring system is made by measuring current and voltage through sensors in real-time to the transformer in the distribution system. Based on the results of the Mamdani Fuzzy Logic Rule test on the input current output containing the transformer and the voltage sensor, the results are obtained in rule with IF inference (Normal Current; (630) AND Voltage (High); (13.2) TRAFFIC) (High Transformer Load). This result can be used as a decision in determining based on simulations performed. The results of Mamdani fuzzy logic inference design on the substation information distribution load on the transformer load 
conditions low, normal, and high, where later students can understand what actions should be taken in this condition, in particular, can consider the transformer maintenance.

\section{ACKNOWLEDGEMENTS}

The authors would like to thank the support of funding this research to Institut Teknologi PLN Jakarta. The authors also thank to anonymous reviewers for their valuable comments to revise the paper

\section{REFERENCES}

[1] T. Cruz et al., "A Cybersecurity Detection Framework for Supervisory Control and Data Acquisition Systems," IEEE Trans. Ind. Informatics, vol. 12, no. 6, pp. 2236-2246, 2016, doi :10.1109/TII.2016.2599841.

[2] A. Ghaleb, S. Zhioua, and A. Almulhem, "SCADA-SST: A SCADA security testbed," in 2016 World Congress on Industrial Control Systems Security, WCICSS 2016, 2017, pp. 34-39, doi :10.1109/WCICSS.2016.7882610.

[3] P. S. S. Shah, S. Raut, D. Jagadale, A. Khatmode, and H. Patil, "IOT Based Industrial SCADA System," Int. Res. J. Eng. Technol., vol. 4, no. 4, pp. 2432-2435, 2017.

[4] Y. Chen and W. Pei, "Design and implementation of SCADA system for micro-grid," Inf. Technol. J., vol. 12, no. 24, pp. 8049-8057, 2013, doi :10.3923/itj.2013.8049.8057.

[5] B. Atlagic, M. Cokic, and M. Ssagi, "Concept of a SCADA system designed for education and research," Appl. Microbiol. Biotechnol., vol. 85, no. 1, pp. 2071-2079, 2014, doi :10.1109/TELFOR.2014.7034586.

[6] M. S. Thomas and J. D. McDonald, "SCADA fundamentals," in Power System SCADA and Smart Grids, pp. 2174, 2015, doi :10.1201/b18338-2.

[7] H. Senyondo, P. Sun, R. Berthier, and S. Zonouz, "PLCloud: Comprehensive power grid PLC security monitoring with zero safety disruption," in 2015 IEEE International Conference on Smart Grid Communications, SmartGridComm 2015, 2016, doi :10.1109/SmartGridComm.2015.7436401.

[8] K. Medrano, D. Altuve, K. Belloso, and C. Bran, "Development of SCADA using a RTU based on IoT controller," in IEEE ICA-ACCA 2018 - IEEE International Conference on Automation/23rd Congress of the Chilean Association of Automatic Control: Towards an Industry 4.0 - Proceedings, 2019, doi :10.1109/ICAACCA.2018.8609700.

[9] E. Nugraha, A. G. Abdullah, and D. L. Hakim, "Designing a SCADA system simulator for fast breeder reactor," IOP Conf. Ser. Mater. Sci. Eng., vol. 128, no. 1, 2016, doi :10.1088/1757-899X/128/1/012006.

[10] M. A. A. IAS G.I., LOLEA M.S., "Scenarios of Regional Power System Expansion from Southern of Bihor County Based on The Exploitation of Renewable Energy Sources," J. Sustain. ENERGY, vol. 9, no. 2, pp. 93-100, 2018.

[11] S. S. W., "Gsm Or X10 Based SCADA System For Industrial Automation," Int. J. Res. Eng. Technol., vol. 02, no. 12, pp. 801-804, 2013, doi :10.15623/ijret.2013.0212133.

[12] K. C. Kao, W. H. Chieng, and S. L. Jeng, "Design and development of an IoT-based web application for an intelligent remote SCADA system," in IOP Conference Series: Materials Science and Engineering, 2018, vol. 323, no. 1 , doi :10.1088/1757-899X/323/1/012025.

[13] R. Hunzinger, "Scada fundamentals and applications in the IoT," in Internet of Things and Data Analytics Handbook, 2017, pp. 283-293, doi :10.1002/9781119173601.ch17.

[14] R. R. Indrianto, I., \& Siregar, "Smart taxi security system design with internet of things (IoT)," TELKOMNIKA (Telecommunication Comput. Electron. Control., vol. 17, no. 3, p. 1250, Jun. 2019, doi: 10.12928/telkomnika.v17i3.10167.

[15] S. A. Moahmmed and P. B. Sattar Sadkhan, "A Comparison of Mamdani and Sugeno Fuzzy Inference Systems based on Block Cipher Evaluation,” Int. J. Sci. Eng. Res., vol. 4, no. 12, pp. 366-371, 2013.

[16] F. Topaloğlu and H. Pehlivan, "Comparison of Mamdani type and Sugeno type fuzzy inference systems in wind power plant installations," in 6th International Symposium on Digital Forensic and Security, ISDFS 2018 Proceeding, vol. 2018-Janua, pp. 1-4, 2018, doi :10.1109/ISDFS.2018.8355384.

[17] D. Hartanti, R. N. Aziza, and P. C. Siswipraptini, "Optimization of smart traffic lights to prevent traffic congestion using fuzzy logic," Telkomnika (Telecommunication Comput. Electron. Control., vol. 17, no. 1, pp. 320-327, 2019, doi :10.12928/TELKOMNIKA.v17i1.10129.

[18] M. Salman AbdulWahed and N. Seno Ismat, "A Comparison of Mamdani and Sugeno Inference Systems for a Satellite Image Classification,” Anbar J. Eng. Sci., vol. العدو الخاص-الجزء الثاني التمر ال, po. pp. 296-306, 2012.

[19] Y. Wang and Y. Chen, "A comparison of Mamdani and Sugeno fuzzy inference systems for chaotic time series prediction," in Proceedings of 2nd International Conference on Computer Science and Network Technology, ICCSNT 2012, 2012, pp. 438-442, doi :10.1109/ICCSNT.2012.6525972.

[20] N. K. Verma, V. Singh, S. Rajurkar, and M. Aqib, "Fuzzy inference network with mamdani fuzzy inference system," in Advances in Intelligent Systems and Computing, vol. 798, pp. 375-388, 2019.

[21] Y. Wang and Y. Chen, "A Comparison of Mamdani and Sugeno Fuzzy Inference Systems for Traffic Flow Prediction,” J. Comput., vol. 9, no. 1, 2014, doi :10.4304/jcp.9.1.12-21.

[22] V. Kamboj and A. Kaur, "Comparison of Constant \{SUGENO-Type\} and \{MAMDANI-Type Fuzzy Inference System for Load Sensor," Int. J. Soft Comput. Eng., vol. 3, no. 2, pp. 204-207, 2013.

[23] M. Blej and M. Azizi, "Comparison of Mamdani-type and Sugeno-type fuzzy inference systems for fuzzy real time scheduling," Int. J. Appl. Eng. Res., vol. 11, no. 22, pp. 11071-11075, 2016. 
[24] Z. Aydogmus, "Implementation of a fuzzy-based level control using SCADA," Expert Syst. Appl., 2009, doi :10.1016/j.eswa.2008.07.055.

[25] K. E. Holbert, A. Mishra, and L. Mill, "Intrusion detection through SCADA systems using fuzzy logic-based state estimation methods," Int. J. Crit. Infrastructures, 2007, doi :10.1504/IJCIS.2007.011545.

[26] J. H. Horng, "SCADA system of DC motor with implementation of fuzzy logic controller on neural network," Adv. Eng. Softw., 2002, doi :10.1016/S0965-9978(02)00020-0.

[27] E. Kamel and A. M. Memari, "State-of-the-Art Review of Energy Smart Homes," J. Archit. Eng., vol. 25, no. 1, p. 03118001, 2019, doi :10.1061/(asce)ae.1943-5568.0000337.

[28] R. R. A. Siregar, "KWh Meter Smart Card Model Token For Electrical Energy Monitoring," MATEC Web Conf., vol. 218, p. 03002, 2018, doi: 10.1051/matecconf/201821803002.

[29] P. C. Siswipraptini, R. Nur Aziza, I. B. M. Sangadji, I. Indrianto, and R. R. A. Siregar, "Automated Smart Home Controller Based on Adaptive Linear Neural Network," 2019 IEEE 7th Int. Conf. Control. Mechatronics Autom. ICCMA 2019, pp. 423-427, 2019, doi: 10.1109/ICCMA46720.2019.8988733.

\section{BIOGRAPHIES OF AUTHORS}
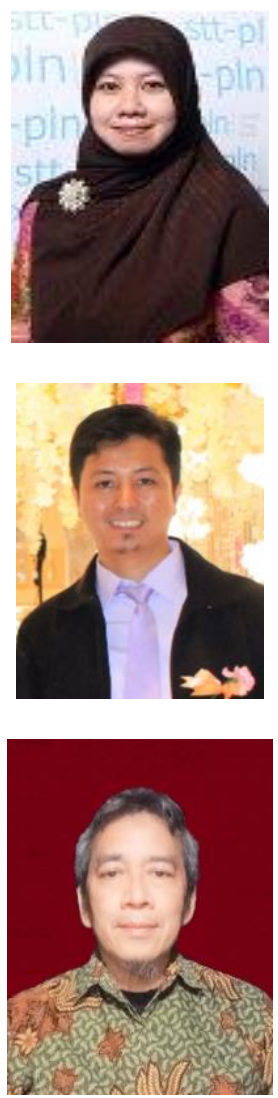

Rahma Farah Ningrum holds a bachelor's degree in computer science and a master's degree in computer science (M.Kom). She currently teaches at the Faculty of Energy Telematics, Institut Teknologi PLN. Several scientific papers that have been published in national journals in Indonesia are "Implementation of Fuzzy Logic in Determining the Pattern of Electric Energy Usage in a Building Based on the results of an Energy Audit", "Designing Multimedia for Introduction to Tourism Objects in West Sumatra" etc. Her contact at email: rahmafarah@itpln.ac.id. https://scholar.google.co.id/citations?user=fmcZSnEAAAAJ\&hl=en

Riki Ruli A. Siregar has a Bachelor of Computer degree in Information Systems Field, Master of Computer Science (M.Kom) in Informatics, Master of Engineering (MT) in Electronics and Telecommunications Engineering, Doctoral Student in Computer Science, in addition to several diplomas and professional expertise. He is currently lecture at the Department of Energy and Telematics, PLN Institute of Technology, Jakarta Indonesia. His research interests include Embedded Systems, Artificial Intelligence, and Computer Science. Contact him at riki.ruli@itpln. ac.id. https://scholar.google.com/citations?user=4laG66UAAAAJ\&hl=en

Darma Rusjdi holds a Bachelor's degree in Architecture Engineering, Master's of Computer (computer science). He is currently lecturing with the department of Telecommunication and Information. https://scholar.google.co.id/citations?hl=id\&user=NhvYBJsAAAAJ 